\title{
The Demand for Aquacultural Products in Taiwan - An Inverse Demand System Approach
}

\author{
Fu-Sung Chiang \\ Associate Professor, Institute of Fisheries Economics, National Taiwan Ocean University, Taiwan, R.O.C. \\ Jonq-Ying Lee \\ Senior Research Economist of the Florida Department of Citrus and an Adjunct Professor of the Food and Resource \\ Economics Department, University of Florida, Gainesville, FL, U.S.A.
}

Follow this and additional works at: https://jmstt.ntou.edu.tw/journal

Part of the Aquaculture and Fisheries Commons, and the Business Commons

\section{Recommended Citation}

Chiang, Fu-Sung and Lee, Jonq-Ying (2000) "The Demand for Aquacultural Products in Taiwan -- An Inverse Demand System Approach," Journal of Marine Science and Technology. Vol. 8: Iss. 2, Article 5.

DOI: 10.51400/2709-6998.2459

Available at: https://jmstt.ntou.edu.tw/journal/vol8/iss2/5

This Research Article is brought to you for free and open access by Journal of Marine Science and Technology. It has been accepted for inclusion in Journal of Marine Science and Technology by an authorized editor of Journal of Marine Science and Technology. 


\section{The Demand for Aquacultural Products in Taiwan - An Inverse Demand System Approach}

\section{Acknowledgements}

The authors thank anonymous reviewers for valuable comments on earlier drafts of this paper. This research was supported by the National Science Council (NSC), NSC 85-2415-H-019-002, Taiwan, Republic of China. The views expressed in this paper are those of the authors' and are not be attributed to NSC. 


\title{
THE DEMAND FOR AQUACULTURAL PRODUCTS IN TAIWAN - AN INVERSE DEMAND SYSTEM APPROACH
}

\author{
Fu-Sung Chiang* and Jonq-Ying Lee**
}

Keywords: Inverse demand system, Demand for aquacultural products, Taiwan.

\begin{abstract}
This study compared two inverse demand systems, the Rotterdam inverse demand system and the Laitinen-Theil inverse demand system, to analyze the demand relationships among aquacultural products in Taiwan. Results demonstrate that the Laitinen-Theil's inverse demand system fits the data better than the Rotterdam inverse demand system. The demand relationships among five groups of aquacultural products, tilapia, milkfish, other aquaculture fish, shrimp, and shellfish were examined. Monthly transaction prices from local fish markets and per capita consumption for the period from July 1990 through December 1995 for these five groups of aquacultural products were used in this study. Results show that milkfish has the absolute highest own-flexibility of 0.495 , which is followed by shrimp, shellfish, tilapia, and other aquacultural fish with their own-flexibilities of $-0.480,-0.283,-0.213$, and -0.090 , respectively. Results also show that a one-percent increase in aggregate quantity of aquacultural products would result in decreases in the normalized prices by $1.57 \%$, $1.04 \%, 1.54 \%, 0.79 \%$, and $0.80 \%$ for tilapia, milkfish, other aquacultural fish, shrimp, and shellfish, respectively.
\end{abstract}

\section{INTRODUCTION}

Aquaculture plays a very important role in Taiwan's fishery. Taiwan's total fishery production in 1998 was 1,348,205 metric tonnes (MT), aquacultural products accounted for $255,218 \mathrm{MT}$, or $19 \%$ of the total fishery production (Taiwan Fisheries Yearbook [1]). In 1998, the total value of aqaucultural products was about NT\$27 billions (or US\$856 millions, see Table 1), or $29 \%$ of total fishery revenues in Taiwan. These figures show that aquacultural products are high-valued products among Taiwan's fishery production.

The major species of aquacultural products are

Paper Received September 27, 2000; Revised October 23, 2000; Accepted November 15, 2000. Author for Correspondence: Fu-Sung Chiang.

*Associate Professor, Institute of Fisheries Economics, National Taiwan Ocean University, Taiwan, R.O.C.

**Senior Research Economist of the Florida Department of Citrus and an Adjunct Professor of the Food and Resource Economics Department, University of Florida, Gainesville, FL, U.S.A. milkfish, tilapia, eel, hard clam, oyster, fresh-water clam, and common carp etc. Strenuous efforts by industries and fishermen combined with and expertise from government, academia, and research institutes have allowed aquaculture in Taiwan to develop rapidly. Aquacultural technologies in Taiwan have gained worldwide reputation. Taiwan's aquacultural sector however is currently facing challenges in its development due to limited land and labor, changes in consumption patterns, and the trend toward global free trade and investment. In order to survive, Taiwan's aquacultural industry needs to develop more capital-intensive technologies, to develop fish-breeding businesses, to seek opportunities of investing overseas, and to adjust its market structure and marketing channels to meet the growing competition from imported seafood.

Aquacultural production increased from 250 thousand MT in 1985 to 344 thousand MT in 1990 then decreased steadily to 255,218 MT in 1998 (Table 1). During the same period, the percentage of aquacultural production to total fishery production decreased from $24 \%$ in 1985 to $19 \%$ in 1990 . The revenue share of aquacultural products also decreased from $41.17 \%$ in 1986 to $28.68 \%$ in 1998 . In 1985 , Taiwan's aquacultural sector employed 81 thousand persons accounting for $24 \%$ of the total employment in the fishery sector.

In recent years, the aquacultural sector accounted for more than $30 \%$ of the employment in the fishery sector (Table 1), indicating that the aquacultural sector provides more employment for fishermen than before. As more fishermen are employed in the aquacultural sector, aquacultural production would likely to increase. An immediate question is what are impact increased aquacultural production will have on its revenue. In order to answer this question, one needs to investigate how the increased aquacultural production affects the prices of these products.

The supply of the aquacultural products is quite inelastic, an indication that an inverse demand system with prices as functions of quantities may be a more appropriate approach to study the demand for aquacultural products than the direct demand system. This 
Table1. Aquacultural production in Taiwan, 1985-1998

\begin{tabular}{|c|c|c|c|c|c|c|c|c|c|}
\hline \multirow{2}{*}{ Year } & \multicolumn{3}{|c|}{ Production (MT) } & \multicolumn{3}{|c|}{ Production Value (Thousand N.T. \$) } & \multicolumn{3}{|c|}{ Fishermen (Person) } \\
\hline & Total (A) & Aquaclture $^{1}(\mathrm{~B})$ & $\%(=\mathrm{B} / \mathrm{A})$ & Total (C) & Aquaculture $^{1}(\mathrm{D})$ & $\%(=\mathrm{D} / \mathrm{C})$ & Total $(\mathrm{E})$ & Aquaculture1 (F) & $\%(=\mathrm{F} / \mathrm{E})$ \\
\hline 1985 & $1,037,721$ & 250,735 & 24.16 & $66,892,998$ & $25,292,728$ & 37.81 & 363,733 & 86,531 & 23.79 \\
\hline 1986 & $1,094,587$ & 266,112 & 24.31 & $75,280,054$ & $30,991,038$ & 41.17 & 309,078 & 87,027 & 28.16 \\
\hline 1987 & $1,236,170$ & 305,428 & 24.71 & $85,954,762$ & $35,232,460$ & 40.99 & 317,318 & 88,103 & 27.76 \\
\hline 1988 & $1,360,868$ & 300,974 & 22.12 & $88,135,707$ & $34,478,389$ & 39.12 & 323,614 & 92,526 & 28.59 \\
\hline 1989 & $1,371,681$ & 249,755 & 18.21 & $89,110,347$ & $26,524,516$ & 29.77 & 327,929 & 94,015 & 28.67 \\
\hline 1990 & $1,455,495$ & 344,263 & 23.65 & $89,154,163$ & $31,530,574$ & 35.37 & 325,902 & 95,656 & 29.35 \\
\hline 1991 & $1,316,651$ & 291,885 & 22.17 & $83,526,072$ & $30,616,203$ & 36.65 & 312,992 & 90,708 & 28.98 \\
\hline 1992 & $1,326,981$ & 261,648 & 19.72 & $83,705,433$ & $29,292,039$ & 34.99 & 286,925 & 99,101 & 34.54 \\
\hline 1993 & $1,423,971$ & 285,275 & 20.03 & $93,175,224$ & $29,815,944$ & 32.00 & 288,350 & 102,921 & 35.69 \\
\hline 1994 & $1,255,273$ & 287,965 & 22.94 & $89,201,376$ & $33,566,439$ & 37.63 & 303,044 & 103,550 & 34.17 \\
\hline 1995 & $1,296,886$ & 286,634 & 22.10 & $100,565,749$ & $36,514,231$ & 36.31 & 302,161 & 98,012 & 32.44 \\
\hline 1996 & $1,239,635$ & 272,525 & 21.98 & $97,431,010$ & $32,727,444$ & 33.59 & 303,153 & 107,599 & 35.49 \\
\hline 1997 & $1,307,066$ & 270,247 & 20.68 & $97,911,265$ & $27,107,058$ & 27.69 & 297,523 & 104,072 & 34.98 \\
\hline 1998 & $1,348,205$ & 255,218 & 18.93 & $95,501,700$ & $27,386,332$ & 28.68 & 297,415 & 99,038 & 33.30 \\
\hline
\end{tabular}

Source: Taiwan Fisheries Yearbook, Fisheries Administration, Council of Agriculture, Taiwan, 1999.

${ }^{1}$ Including marine culture and inland culture.

study uses two competing inverse demand systems, the Rotterdam inverse demand system and the LaitinenTheil [2] inverse demand system, to study the demand for aquacultural products in Taiwan. Based on the goodness-of-fit, one of the two inverse demand systems will be chosen to analyze the demand for aquacultural products in Taiwan.

In the next section, we first introduce the Rotterdam inverse demand system (RIDS) and the Laitinen-Theil [2] inverse demand system. Then describe the data used in this analysis. Empirical results of this study are then discussed and concluding remarks are given in the final section.

\section{THE INVERSE DEMAND MODELS}

A system of inverse demand equations can be obtained by minimizing the indirect utility function subject to the budget constraint (Weymark [3]). Formally, the problem can be written as

$$
\begin{aligned}
& \min \psi(\pi) \\
& \text { s.t. } \pi^{\prime} x=1 \\
& x=k x^{*}
\end{aligned}
$$

where $\psi$ is the indirect utility function, $\pi$ is a vector of normalized prices $\left(\pi_{i}=p_{i} / m\right)$, and $x$ is a vector of quantities. The normalized price vector $\pi$ is equal to $\mathrm{p} /$ $m$, where $p$ is a vector of actual prices and $m$ is total expenditure or income. The indirect utility function $\psi$ $(\pi)$ is continuous, decreasing and quasiconvex in $\pi$ (instead of quasiconvexity, one might assume strict convexity, a slightly stronger assumption on the curvature of $\psi$ ). In order to find out the effect of a proportional change in all $x_{i} s$ on the indirect utility and prices, let $x=k x^{*}$, where $k$ is a scalar and $x^{*}$ is some reference quantity vector.

For the present analysis, $x$ is assumed positive. Furthermore, from the standpoint of the consumer, they are regarded as given. Minimization of the indirect utility function subject to the budget constraint is carried out by the Lagrangian method. According to this procedure, one forms the expression

$$
L(\pi, \lambda)=\psi(\pi)-\lambda\left(\pi^{\prime} x-1\right)
$$

where $\lambda$ is the Lagrangian multiplier. Differentiating the Lagrangian equation (2) above with respect to each of the arguments, $\pi_{i}$ and $\lambda$, yields the first-order conditions

$$
\begin{aligned}
& \partial L / \partial \pi_{i}=\partial \psi / \partial \pi_{i}-\lambda x_{i}=0 \quad \text { or } \quad \psi_{i}=\lambda x=\lambda k x^{*} \\
& \partial L / \partial \lambda=\pi^{\prime} x-1=0 \quad \text { or } \quad \pi^{\prime} x=\pi^{\prime} k x^{*}=1
\end{aligned}
$$

where $\psi_{i}$ is the vector of derivatives of the indirect utility function with respect to the normalized prices, $i$. e., $\psi_{i}=\partial \psi / \partial \pi_{i}, i=1,2, \ldots, n$.

Second-order conditions for a maximum can be written as

$$
y^{\prime} \Psi y \geq 0, \text { for all } y \text { such that } x^{\prime} y=0 .
$$


The Hessian matrix $\Psi=\left[\psi_{i j}\right]$ is defined as

$$
\left[\psi_{i j}\right]=\partial^{2} \psi / \partial \pi_{i} \partial \pi_{j}
$$

The second-order conditions are assured by the assumption that the indirect utility function $\psi$ is strictly quasi-convex.

Applying the implicit function theorem, the system (3) can be solved uniquely for $\pi$ and $\lambda$ in terms of quantities. The resulting expressions are

$$
\begin{aligned}
& \pi=\pi(x)=\pi\left(k x^{*}\right) \\
& \lambda=\lambda(x)=\lambda\left(k x^{*}\right)
\end{aligned}
$$

Consider now the differential demand system. The total differential of $\pi_{i}$ can be written as

$$
d \pi_{i}=\Sigma_{j}\left(\partial \pi_{i} / \partial x_{j}\right) d x_{j}, \text { or }
$$

where $\partial \pi_{i} / \partial x_{j}$ is the impact of a change in $x_{j}$ on the normalized price $\pi_{i}$. Note that $\partial \pi_{i} / \partial x_{j}$ can be decomposed into the Antonelli substitution effect and the scale effect (Anderson [4]), i.e.,

$$
\partial \pi_{i} / \partial x_{j}=f_{i j}+k \pi_{i}\left(\partial \pi_{i} / \partial k\right)
$$

where $f_{i j}$ is the Antonelli substitution effect and $k \pi_{j}\left(\partial \pi_{i} /\right.$ $\partial k)$ is the scale effect of a change in $x_{j}$ on $\pi_{i}$. Using this relationship, (7) can be rewritten as

$$
d \pi_{i}=\Sigma_{j}\left(f_{i j}+k \pi_{j}\left(\partial \pi_{i} / \partial k\right)\right) d x_{j}
$$

Multiplying both sides by $x_{i}$ and rearranging terms yields

$$
\begin{aligned}
x_{i} \pi_{i}\left(d \pi_{i} / \pi_{i}\right)= & \Sigma_{j} x_{i} x_{j}\left(f_{i j}+k \pi_{j}\left(\partial \pi_{i} / \partial k\right)\right)\left(d x_{j} / x_{j}\right) \\
= & \Sigma_{j} x_{i} x_{j} \pi_{j} k\left(\partial \pi_{i} / \partial k\right)\left(d x_{j} / x_{j}\right) \\
& +\Sigma_{j} x_{i} x_{j} f_{i j}\left(d x_{j} / x_{j}\right) \\
= & x_{i} \pi_{i}\left(\partial \pi_{i} / \partial k\right)\left(k / \pi_{i}\right) \Sigma_{j} x_{j} \pi_{j}\left(d x_{j} / x_{j}\right) \\
& +\Sigma_{j} h_{i j}\left(d x_{j} / x_{j}\right), \text { or } \\
w_{i}\left(d \pi_{i} / \pi_{i}\right)= & w_{i} \Delta_{i} \Sigma_{j} w_{j}\left(d x_{j} / x_{j}\right)+\Sigma_{j} h_{i j}\left(d x_{j} / x_{j}\right)
\end{aligned}
$$

where $\Delta_{i}$ is the scale elasticity for commodity $i, h_{i j}=$ $x_{i} x_{j} f_{i j}=x_{i} \pi_{i} f_{i j}\left(x_{j} / \pi_{i}\right)=w_{i} \Delta_{i j}{ }^{*}$, and $\Delta_{i j}{ }^{*}$ is the scale compensated quantity elasticity. If one defines $h_{i}=w_{i} \Delta_{i}$, $\operatorname{d} \ln X=\Sigma_{j} w_{j}\left(d x_{j} / x_{j}\right)$ (the Divisia volume index), and using the definition of $\operatorname{d} \ln x_{i}=d x_{i} / x_{i}$, the above relationship can be rewritten as

$$
w_{i} \mathrm{~d} \ln \pi_{i}=h_{i} \mathrm{~d} \ln \mathrm{X}+\sum_{j} h_{i j} \mathrm{~d} \ln x_{j} .
$$

This is the Rotterdam inverse demand system
(RIDS, Barten and Bettendorf [5]). The demand restrictions require the demand parameters in (12) satisfy the following conditions

$$
\begin{aligned}
& \Sigma_{i} h_{i}=-1 \text { and } \Sigma_{i} h_{i j}=0 ; \\
& \text { adding-up (Engel and Cournot) } \\
& \Sigma_{j} h_{i j}=0 ; \text { homogeneity } \\
& h_{i j}=h_{j i} \text { symmetry }
\end{aligned}
$$

In estimating the RIDS, parameters $h_{i}$ and $h_{i j}$ are treated as constants. However, $h_{i}$ s do not have to be constants. If one adds $w_{i} \mathrm{~d} \ln X$ to both sides of (12), one obtains

$$
\begin{aligned}
& w_{i}\left(d \ln \pi_{i}+\mathrm{d} \ln X\right)=\left(w_{i}+h_{i}\right) \mathrm{d} \ln X+\Sigma_{j} h_{i j} d \ln x_{j} ; \text { or } \\
& w_{i}\left(d \ln \pi_{i}+\mathrm{d} \ln X\right)=b_{i} d \ln X+\Sigma_{j} h_{i j} d \ln x_{j} ;
\end{aligned}
$$

where $b_{i}=w_{i}+h_{i}$. In (14), the adding-up condition requires $\Sigma_{i} b_{i}=0$. The inverse demand system shown in (14) was first derived by Laitinen and Theil [2]. The Laitinen-Theil inverse demand system can be viewed as a special parameterization of the RIDS with $h_{i}=b_{i}-w_{i}$.

In general, for models (12) and (14), the scale elasticity for each commodity $\left(\Delta_{i}\right)$ can be derived by dividing the scale parameter, $h_{i}$ or $\left(b_{i}-w_{i}\right)$ by the corresponding budget share. The uncompensated quantity elasticity estimates $\left(\Delta_{i j}\right)$ can be derived using the Antonelli parameter and budget share

$\Delta_{i}=h_{i} / w_{i}$, or Scale elasticity for the RIDS

$\Delta_{i}=\left(h_{i}-w_{i}\right) / w_{i}=b_{i} / w_{i}-1$;

Scale elasticity for the Laitinen-Theil model

$\Delta_{i j}=h_{i j} / w_{i}-w_{j} \Delta_{i}$.

Uncompensated quantity elasticity

Note that models (12) and (14) are not nested, however, they are both nested within a more general model proposed by Barten [6]:

$$
w_{i} \mathrm{~d} \ln \pi_{i}=d_{i} \mathrm{~d} \ln X+\sum_{j} h_{i j} \mathrm{~d} \ln x_{i}-\delta w_{i} \mathrm{~d} \ln X
$$

Model (16) is the RIDS when $\delta=0$ and the LaitinenTheil model when $\delta=1$. Accordingly, one can perform likelihood ratio tests (LRT) comparing the RIDS and Laitinen-Theil models to (16) in order to choose between the functional form of the RIDS versus the Laitinen-Theil model for a particular data set. The demand restrictions for equation (16) are

$$
\begin{array}{ll}
\Sigma_{i} d_{i}=1-\delta \text { and } \Sigma_{i} h_{i j}=0 ; & \text { Adding-up } \\
\Sigma_{j} h_{i j}=0 ; & \text { Homogeneity }
\end{array}
$$




$$
h_{i j}=h_{j i} . \quad \text { Symmetry }
$$

The LRT for model selection is

$$
\text { LRT }=-2\left[\log L\left(\theta^{*}\right)-\log L(\theta)\right]
$$

where $\theta^{*}$ is the vector of parameter estimates of either the RIDS (12) or the Laitinen-Theil inverse demand system (14); $\theta$ is the vector of parameter estimates of the general model (16); and $L($.$) is the \log$ value of the likelihood function (Amemiya, pp. 141-146 [7]). For example, under the null hypothesis that the RIDS best describes the data, test statistic LRT has an asymptotic $\chi^{2}(q)$ distribution. Where $q=1$ is the number of restrictions imposed (i.e., the degrees of freedom equal to the difference between the number of parameters in the general model and the RIDS).

\section{THE DATA}

Five types of aquacultural products are examined: tilapia, milkfish, other aquacultural fish, shrimp, and shellfish. Average monthly retail price from fish markets and per capita consumption for the five aquacultural products for the July 1990 through December 1995 period were used. There are 66 observations.

The price and quantity information for the five aquacultural products came from six data sources: (1) Taiwan Fisheries Yearbook, Fisheries Administration, Council of Agriculture, Executive Yuan, R.O.C.; (2) Daily Fish Markets' Transaction Data in Taiwan Area, Fisheries Administration; (3) Monthly Statistics of Imports and Exports, Directorate-General of Customs, Ministry of Finance, Executive Yuan, R.O.C.; (4) Agricultural Trade Statistics of the Republic of China, Council of Agriculture, Executive Yuan, R.O.C.; (5) Commodity-Price Statistics Monthly in Taiwan Area of the Republic of China, Directorate-General of Budget, Accounting and Statistics, Executive Yuan, R.O.C.; and (6) Taiwan Population Statistics, Ministry of the Interior, Executive Yuan, R.O.C.

Five different groups of aquacultural products are selected: tilapia, milkfish, other aquaculture fish, shrimp, and shellfish. Although these types of aquacultural products differ in taste and appearance, they are close substitutes from the viewpoint of Taiwanese consumers. These five types of aquacultural products accounted for $77.06 \%$ and $70.25 \%$ of total production and value (Table 2). Traditionally, milkfish (Canos chanos) and tilapia (Tilapia mossambica) are the most important species in the aquacultural sector in Taiwan. These two species accounted for $22.87 \%$ and $14.15 \%$ of total aquacultural production in 1998. Besides the milkfish and tilapia, five fish species were also selected and combined as a composite commodity, namely "other aquacultural fish." These five fish species are common carp (Cyprinus carpio), crucian carp (Carassius auratus), grass carp (Ctenopharyngodon fdellus), black silver carp (Aristichthys nobilis), and silver carp (Hypophthalmichthys molitrix). The "shrimp" group consisted of five species: grass shrimp (Penaeus monodon), sand shrimp (Metapenaeus ensis), giant freshwater prawn (Parapenaeus longipes), red tail shrimp (Penaeus penicillatus), and Kuruma shrimp (Penaeus Japonicus). Oyster (Crassostrea gigas), hard clam (Meretrix lusoria), short-necked clam (Parhia euglypta), small abalones (Sulculus diversicolor aqualilis), purple clam (Soletllina diphus), and fresh water clam (Corbicula fluminea) were grouped as the "shellfish" group.

Consumption data of aquacultural products are not available. The per capita consumption of aquacultural products used in this study was derived from production data. Generally, we can use the production figures as the base and adjust for imports and exports. The results are the availability of aquacultural products or the disappearance data. Monthly disappearance data for the five groups of fishery products were calculated. The per capita consumption data were derived by dividing the disappearance quantities by population. The use of per capita consumption in the estimation can induce homoscedasticity (Theil and Clements [8]). Price information was gathered in local fish markets. Prices for eighteen species were collected. The prices for the five groups were weighted average prices for the species in each group.

The sample means of prices and expenditure shares and total productions of these five groups of aquacultural products for years 1991 through 1995 are reported (Table 3). There were no clear time trends in the productions of these five groups of aquacultural products except that milkfish production had increased. The shrimp group had the highest unit price among the five groups studied. In addition, the price of shrimp increased from NT\$140 per kilogram in 1991 to NT\$233 per kilogram in 1995, an increase of $67 \%$. Revenues from tilapia, milkfish, and shrimp increased over the 1991 through 1995 period. Shrimp had the largest revenue shares, which is followed by milkfish, shellfish, tilapia, and other fish.

The supplies of these five groups of aquacultural

\footnotetext{
${ }^{1}$ The share is the sum of five groups of aquacultural products over total aquacultural production (eels are export-oriented, therefore was not included in the calculation), i.e., $(183,379 / 237,977) * 100=77.06 \%$.
} 
Table 2. Aquacultural production in Taiwan, by Major Species, 1998

\begin{tabular}{lcccc}
\hline Species & $\begin{array}{c}\text { Quantity } \\
\text { (MT) }\end{array}$ & $\begin{array}{c}\text { Percentage of Total } \\
\text { Aquacultural } \\
\text { production }^{1}(\%)\end{array}$ & $\begin{array}{c}\text { Value } \\
\text { (Thousand N.T. }\end{array}$ & $\begin{array}{c}\text { Percentage of Total } \\
\text { Aquacultural production } \\
\text { Value }^{2}(\%)\end{array}$ \\
\hline Milkfish & 58,349 & 22.87 & $2,502,175$ & 9.14 \\
Tilapia & 36,126 & 14.15 & $1,106,183$ & 4.04 \\
Eel & 17,241 & 6.76 & $6,024,979$ & 22.00 \\
Common carp & 3,319 & 1.30 & 113,329 & 0.41 \\
Crucian carp & 2,364 & 0.93 & 120,199 & 0.44 \\
Grass carp & 4,472 & 1.75 & 246,878 & 0.90 \\
Black silver carp & 3,266 & 1.28 & 132,633 & 0.48 \\
Grass shrimp & 4,812 & 1.89 & $1,485,751$ & 5.43 \\
Sand shrimp & 186 & 0.07 & 88,446 & 0.32 \\
Giant freshwater prawn & 8,165 & 3.20 & $2,600,691$ & 9.50 \\
Red tail shrimp & 137 & 0.05 & 33,278 & 0.12 \\
Kuruma shrimp & 355 & 0.14 & 129,094 & 0.47 \\
Oyster & 19,386 & 7.60 & $3,388,658$ & 12.37 \\
Hard clam & 25,874 & 10.14 & 838,099 & 3.06 \\
Short-necked clam & 923 & 0.36 & 73,824 & 0.27 \\
Small abalones & 2,312 & 0.91 & $1,478,481$ & 5.40 \\
Purple clam & 276 & 0.11 & 34,066 & 0.12 \\
Fresh water clam & 13,057 & 5.12 & 634,794 & 2.32 \\
Total & 200,620 & 78.63 & $21,031,558$ & 76.79 \\
\hline Sourc: Taiwan & & &
\end{tabular}

Source: Taiwan Fisheries Yearbook, Fisheries Administration, Council of Agriculture, Taiwan, 1999.

${ }^{1}$ Total aquacultural production (including marine culture and inland culture) in 1998 was 255,218 MT. For the case of milkfish, $58,349 / 255,218=22.87 \%$.

${ }^{2}$ Total aquacultural production value (including marine culture and inland culture) in 1998 was 27,386,332 thousand N.T. dollars. For the case of milkfish, 2,502,175/27,386,332 $=9.14 \%$.

products are highly seasonal. Tilapia's harvest season peaks from November to December, and the peak period for milkfish is from May to November. To eliminate seasonality from the data series (Duffy [9]), the twelfthdifferences were used, i.e., $w_{i t}=\left(w_{i t}+w_{i t-12}\right) / 2, \mathrm{~d} \ln \pi_{i t}$ $=\log \left(\pi_{i t} / \pi_{i t-12}\right), \mathrm{d} \ln x_{i t}=\log \left(x_{i t} / x_{i t-12}\right)$ were used in (12), (14), and (16).

\section{EMPIRICAL RESULTS}

The full information maximum likelihood procedure (TSP) was used to estimate models (12) and (14) with errors across equations assumed to be contemporaneously correlated. The likelihood functions are 512 . 25, 505.78, and 499.12, respectively, for (16), (14), and (12). Since the model is estimated by maximum likelihood procedure, the LRT is used. Using the LRT shown in (18), the test results show that the Laitinen-Theil inverse demand system fits the data better than do the RIDS. Accordingly, only the results based on the Laitinen-Theil inverse demand system are reported and discussed further below.

The scale and uncompensated quantity elasticity estimates for the Laitinen-Theil model confirmed to the theoretical expectations. Sample-mean expenditure shares were used to derive these estimates. The scale elasticity estimates imply that if the supply of all aquacultural products is increased by one percent, the prices of tilapia, milkfish, and other aquacultural fish would go down by $1.57 \%, 1.04 \%$ and $1.53 \%$, respectively. Shrimp and Shellfish will only be affected by a $0.79 \%$ and $0.8 \%$ price decline. This result indicates that the scale change in aquacultural production had higher impacts on fish prices than on the prices of shellfish.

The uncompensated own-quantity elasticities or flexibilities for the Laitinen-Theil model in table 4 are consistent with theory with negative signs. Results of this study indicates that milkfish has the highest absolute own-flexibility at 0.495 among the five aquacultural products. The own-flexibilities for shrimp, shellfish, tilapia, and other aquaculture fish are -0.480 , $-0.283,-0.213$, and -0.090 , respectively. This result indicates that the prices of milkfish and shrimp are more sensitive to production changes than the prices of tilapia, other fish, and shellfish.

Cross-flexibilities show the impact of a one per- 
Table 3. Sample statistics — 1991 through 1995

\begin{tabular}{|c|c|c|c|c|c|}
\hline Year & Tilapia & Milkfish & Other Fish & Shrimp & Shellfish \\
\hline & & & Revenue Share & & \\
\hline 1991 & $7.2 \%$ & $37.7 \%$ & $5.9 \%$ & $35.5 \%$ & $13.7 \%$ \\
\hline 1992 & $10.8 \%$ & $12.9 \%$ & $7.8 \%$ & $49.7 \%$ & $18.8 \%$ \\
\hline 1993 & $15.0 \%$ & $17.2 \%$ & $10.9 \%$ & $37.3 \%$ & $19.5 \%$ \\
\hline 1994 & $13.6 \%$ & $22.8 \%$ & $7.6 \%$ & $41.3 \%$ & $14.8 \%$ \\
\hline \multirow[t]{2}{*}{1995} & $10.9 \%$ & $22.6 \%$ & $8.6 \%$ & $42.9 \%$ & $14.9 \%$ \\
\hline & & & Quantity Share & & \\
\hline 1991 & $23.8 \%$ & $19.1 \%$ & $11.8 \%$ & $18.4 \%$ & $26.9 \%$ \\
\hline 1992 & $25.8 \%$ & $13.6 \%$ & $12.4 \%$ & $13.8 \%$ & $34.4 \%$ \\
\hline 1993 & $27.2 \%$ & $21.5 \%$ & $10.4 \%$ & $12.7 \%$ & $28.2 \%$ \\
\hline 1994 & $21.3 \%$ & $29.6 \%$ & $11.7 \%$ & $11.5 \%$ & $25.8 \%$ \\
\hline \multirow[t]{2}{*}{1995} & $20.8 \%$ & $28.1 \%$ & $9.9 \%$ & $15.5 \%$ & $25.8 \%$ \\
\hline & & & Production (MT) & & \\
\hline 1991 & 51,412 & 41,293 & 25,375 & 39,607 & 58,025 \\
\hline 1992 & 47,853 & 25,142 & 23,093 & 25,648 & 63,764 \\
\hline 1993 & 57,570 & 45,523 & 22,080 & 26,817 & 59,731 \\
\hline 1994 & 48,040 & 66,804 & 26,460 & 25,907 & 58,229 \\
\hline \multirow[t]{2}{*}{1995} & 46,792 & 63,254 & 22,204 & 34,778 & 57,937 \\
\hline & & & Revenue (NT\$1,000) & & \\
\hline 1991 & $1,196,219$ & $1,435,078$ & 867,669 & $5,526,838$ & $2,090,392$ \\
\hline 1992 & $1,495,250$ & $1,713,811$ & $1,086,081$ & $3,709,517$ & $1,934,328$ \\
\hline 1993 & $1,568,860$ & $2,640,400$ & 875,558 & $4,773,671$ & $1,712,840$ \\
\hline 1994 & $1,426,528$ & $2,946,220$ & $1,122,154$ & $5,596,875$ & $1,948,026$ \\
\hline \multirow[t]{2}{*}{1995} & $1,694,379$ & $3,510,427$ & $1,039,408$ & $8,088,439$ & $2,121,684$ \\
\hline & & & Average Price $(\mathrm{NT} \$ / \mathrm{kg})$ & & \\
\hline 1991 & 23.27 & 34.75 & 34.19 & 139.54 & 36.03 \\
\hline 1992 & 31.25 & 68.17 & 47.03 & 144.63 & 30.34 \\
\hline 1993 & 27.25 & 58.00 & 39.65 & 178.01 & 28.68 \\
\hline 1994 & 29.69 & 44.10 & 42.41 & 216.04 & 33.45 \\
\hline 1995 & 36.21 & 55.50 & 46.81 & 232.57 & 36.62 \\
\hline
\end{tabular}

Table 4. Scale Elasticity and Flexibility Estimates for the Laitinen-Theil Model

\begin{tabular}{|c|c|c|c|c|c|c|}
\hline \multirow[t]{2}{*}{ Species } & \multirow{2}{*}{$\begin{array}{c}\text { Scale } \\
\text { Elasticity }\end{array}$} & \multicolumn{5}{|c|}{ Flexibilities Estimates } \\
\hline & & Tilapia & Milkfish & Other F. & Shrimp & Shellfish \\
\hline \multirow[t]{2}{*}{ Tilapia } & $-1.567^{*}$ & -0.213 & $-0.258 *$ & $-0.185^{*}$ & $-0.589 *$ & $-0.322 *$ \\
\hline & $(0.368)^{\mathrm{a}}$ & $(0.132)$ & $(0.072)$ & $(0.088)$ & $(0.085)$ & $(0.162)$ \\
\hline \multirow[t]{2}{*}{ Milkfish } & $-1.035^{*}$ & -0.094 & $-0.495^{*}$ & -0.047 & -0.276 & -0.122 \\
\hline & $(0.323)$ & $(0.052)$ & $(0.079)$ & $(0.042)$ & $(0.189)$ & $(0.097)$ \\
\hline \multirow[t]{2}{*}{ Other F. } & $-1.543^{*}$ & $-0.265^{*}$ & $-0.212^{*}$ & -0.090 & $-0.709 *$ & $-0.266^{*}$ \\
\hline & $(0.328)$ & $(0.122)$ & $(0.042)$ & $(0.163)$ & $(0.087)$ & $(0.128)$ \\
\hline \multirow[t]{2}{*}{ Shrimp } & $-0.786^{*}$ & -0.075 & -0.080 & $-0.078 *$ & $-0.480^{*}$ & -0.073 \\
\hline & $(0.263)$ & $(0.066)$ & $(0.049)$ & $(0.039)$ & $(0.111)$ & $(0.075)$ \\
\hline \multirow[t]{2}{*}{ Shellfish } & $-0.802 *$ & -0.147 & -0.102 & -0.075 & $-0.195^{*}$ & -0.283 \\
\hline & $(0.327)$ & $(0.112)$ & $(0.054)$ & $(0.071)$ & $(0.093)$ & $(0.187)$ \\
\hline
\end{tabular}

${ }^{\mathrm{a}}$ Asymptotic standard errors in parentheses.

*Statistically different from zero at $\alpha=0.05$ level.

cent increase in the production of one group of fish on the prices of other fish. For example, the estimates in Table 4 show that if milkfish production is increased by one percent, the price of tilapia, other fish, shrimp, and shellfish would decrease by $0.26 \%, 0,21 \%, 0.08 \%$, and $0.10 \%$, respectively. This example shows that the increased milkfish production had larger impacts on the prices of fish groups (i.e., tilapia and other fish) than on 
shellfish groups (shrimp and other shellfish). As shown in Table 4, the estimated cross-flexibilities are about the same magnitude of own-flexibility estimates and sometimes are higher than own-flexibilities, an indication that these aquacultural products are close substitutes.

\section{CONCLUDING REMARKS}

This study compared two inverse demand systems, the Rotterdam inverse demand system and the LaitinenTheil inverse demand system, to analyze the demand relationships among aquacultural products in Taiwan. Results demonstrate that the Laitinen-Theil's inverse demand system fits the data better than the Rotterdam inverse demand system. The demand relationships among five groups of aquacultural products, tilapia, milkfish, other aquaculture fish, shrimp, and shellfish were examined. Monthly prices from local fish markets and per capita consumption for the period from July 1990 through December 1995 for these five groups of aquacultural products were used in this study.

The findings shown above indicate that when the production of any one of these five groups of aquacultural products is increased, the total revenue of this group would increase. Therefore, perhaps, there is an incentive to increase the production of these groups individually. Based on the flexibility estimates obtained in this study, the impact of increased production on own-price is lower for tilapia and shellfish groups than for the milkfish and shrimp groups. In other words, the impacts of increased production would have less impact on the prices of tilapia and shellfish groups than on the prices of milkfish and shrimp groups. If the production of all five groups were increased proportionally, then the prices of tilapia and other fish would be decreased more than proportionally, i.e., a one percent increase in scale would reduce the prices of tilapia and other fish groups by more than $1.5 \%$.

This study used aggregated data, the sum of all individual consumption. There are discussions of how to deal with this aggregation problem in the direct demand system - essentially, the propensities to consume are different in different income groups. However, none of literatures show how to deal with this problem in the indirect demand analysis. Certainly, the aggregation will have an impact on the flexibility estimates. But how and what need to be explored in the future.

\section{ACKNOWLEDGEMENT}

The authors thank anonymous reviewers for valuable comments on earlier drafts of this paper. This research was supported by the National Science Council (NSC), NSC 85-2415-H-019-002, Taiwan, Republic of
China. The views expressed in this paper are those of the authors' and are not be attributed to NSC.

\section{REFERENCES}

1. Fisheries Administration, Taiwan Fisheries Yearbook, Council of Agriculture, Taiwan (1999).

2. Laitinen, K. and H. Theil, "The Antonelli Matrix and Reciprocal Slutsky Matrix," Economic Letters, 3: 153157 (1979).

3. Weymark, J. A., "Duality Results in Demand Theory," European Economic Review, 14: 377-395 (1980).

4. Anderson, R.W., "Some Theory of Inverse Demand for Applied Demand Analysis," European Economic Review, 14: 281-290 (1980).

5. Barten, A. P. and L. J. Bettendorf, "Price Formation of Fish: An Application of an Inverse Demand System," European Economic Review, 33: 1509-1525 (1989).

6. Barten, A. P., "Consumer Allocation Models: Choice of Functional Form," Empirical Economics, 18: 129-158 (1993).

7. Amemiya, T., Advanced Econometrics, Harvard University Press, (1987).

8. Theil, H. and K. W. Clements, "A Differential Approach to U.S. Import Demand," Economics Letters, 1: 249-252 (1978).

9. Duffy, M., "Advertising and Alcoholic Drink Demand in the UK: Some further Rotterdam Model Estimates," International Journal of Advertising, 9: 247-257 (1990).

\section{台灣養殖產品總和需求之研究一逆 需求體系之應用 \\ 江 福 松}

國立䓨灣海洋大學漁業經濟研究所

李 仲英

美國佛州柑橘部暨佛大糧食與資源經濟系

摘 要

本研究以國内主要的養殖產品 (吴郭魚、虫目 魚、其它養殖魚類、蝦類、及貝類）爲研究對象, 就 其供給是相當地缺乏彈性(Inelastic) 的特性, 應用三 類逆需求體系(Inverse Demand System)模型進行宣 證分析並選擇出最適模型--Laitinen-Theil模型, 以 建立國内養殖產品之需求體系, 並求算出規模彈性及 價格反應彈性。研究結果顯示虫目,魚的可供消費量對 養殖產品價格的影響較其它養殖產品來得顯著。 